\title{
Using social representations theory to make sense of climate change: what scientists and nonscientists in Australia think
}

\author{
Gail Molonev $^{1}, \underline{\text { Zoe Leviston }}^{2}$, Timothy Lynam $^{3}{ }^{\text {, Jennifer Price }}{ }^{2}$, Samantha Stone-Jovicich ${ }^{2}$ and Duncan Blair ${ }^{2}$
}

\begin{abstract}
The mass media has ensured that the challenging and complex phenomenon of climate change now has the household familiarity of a brand name. But what is it that is understood by climate change, and by whom? What frame of reference is drawn upon to communicate meaningfully about climate change? Do particular subgroups within our society hold different understandings, or have the debate and the prolific dissemination of information about this issue coalesced around a core perception or image of what climate change is? To answer these questions, we conceptualized climate change within the theory of social representations as emergent socially constructed knowledge. We analyzed word association data collected in Australia from persons identifying as having a scientific, government, or general public background $(N=3300)$. All respondents were asked to write the first words that came to mind when they thought about climate change. Comparative analyses of the word associations reveal that respondents from different backgrounds define climate change in different ways. The results suggest that there is a common core set of concepts shared by the different groups, but there are also a great many differences in how climate change is framed and conceived by respondents. The results are discussed in relation to what they imply for responses to climate change by these social groups and in relation to interventions designed to encourage climate adaptation.
\end{abstract}

Key Words: adaptation; climate change; social representations theory; word associations

\section{INTRODUCTION}

There are several experiential, ontological, and epistemological characteristics of climate change that have led some to claim that it is the ultimate "wicked problem" (Australian Public Services Commission 2007, Noble and Bennett 2007, Lazarus 2009). Notwithstanding the scale, magnitude, and uncertainty of effects, it is the intangibility of climate change that is most vexing. Attempts to communicate about climate change have been beset by problems stemming from the difficulty of articulating the nature of the risk; risk that develops over long time periods and often in an elusive manner (Weingart et al. 2000, Lorenzoni et al. 2007, Doyle 2009). Climate change cannot, generally speaking, be seen, smelled, heard, or touched as a discernible object. In this respect, it exists in the realm of the conceptual, making it difficult for people to understand fully (O'Neill and Hulme 2009).

Despite the intangibility of climate change, people still need to make sense of it, not least because of its persistent presence in the media. "Disturbances of communication" between science, politics, and the media have come to define climate change as an issue, generating uncertainty within the public and hindering appropriate action to mitigate and respond to the risk (Weingart et al. 2000). Baer and Risbey (2009) see cognitions, or thoughts, about climate change as being dependent on value-laden judgements about the nature and distribution of the risks it poses. More recent findings from the UK (Whitmarsh 2011) indicate that individuals' environmental and political views strongly determine their beliefs about climate change, in particular, their level of scepticism. In a review of individual perceptions and understandings of climate change, Wolf and Moser (2011:562) note that perceptions of climate change are often linked to "other, not necessarily environmental, issues". Accordingly, increased attention has been paid to what it is that people understand by climate change, including the direct and indirect associations the concept might stimulate.

\section{Previous research on climate change understandings}

The most comprehensive research to date on what people understand climate change to be has been conducted in the USA and UK using word association techniques. Leiserowitz (2006) conducted a survey of 673 people in the United States in which people were asked to provide the first thought or image that came to mind when they thought of the words "global warming". The top eight categories, accounting for $97 \%$ of responses, were: melting ice, heat, nature, ozone, alarmists (images of devastation), floods/sea-level rise, climate change, and naysayers. Leiserowitz concluded that $61 \%$ of the Americans surveyed provided associations to geographically and psychologically distant climate change impacts and lacked vivid, concrete, and personally relevant, emotionally laden images of climate change.

In a cross-national (USA, UK) comparison of people's image associations with climate change and global warming, Lorenzoni et al. (2006) found both differences and similarities between the two nations in the types of images associated with climate change. Images of weather were more frequently cited by UK respondents, whereas images of ice melting, natural disasters, and scepticism were more common among U.S. respondents. UK respondents also had a higher proportion of respondents for whom an image did not come to mind. At a more general level, there was a prevalence of negative, psychologically distant associations for respondents from both nations, with personally relevant impacts and solutions rarely mentioned.

Understanding how people construct and represent climate change is critical in light of recent findings suggesting that certain visual and mental imagery can provoke counter-productive responses (see Nicholson-Cole 2005). Specifically, negative, distant associations and ideas may lead to issue-avoidance, disempowerment, and feelings that climate change issues are too overwhelming for individuals to respond effectively (O'Neill and Nicholson-Cole 2009). It is argued that people tend to be more 
concerned with the state of the environment at a global rather than a local level (Dunlap et al. 1993, Lima and Castro 2005), and this has been observed in relation to climate change (Lorenzoni et al. 2005). Whether the prevalence of negative and distant associations is also evident in Australian understandings of climate change (given the different roles played by media, government agencies, and different climatic impacts of climate change) is presently unknown.

To our knowledge, a systematic investigation of what is understood by, or about, climate change has not been conducted in Australia. Although some studies have looked at specific groups' perceptions of climate change risks (e.g., see Bardsley and Wiseman 2012), we are not aware of any previous research exploring whether and how understandings of climate change differ across segments of society. Thus, our aim was to investigate what is understood by the term "climate change" in Australia. More specifically, we were interested in how these understandings might vary across different social groups. Here, we present the results of a large-scale investigation of associations of climate change elicited from scientists, government employees, and the general public. We articulate our findings through the theoretical framework of social representations theory (Moscovici 1984).

\section{Social representations theory}

Social representations theory is a "theory of social knowledge" specifically concerned with how individuals, groups, and communities collectively make sense of socially relevant or problematic issues, ideas, and practices (Marková 2008:483). Research within this framework has investigated complex and challenging social phenomena such as HIV/AIDS, mental illness, and human rights. It has also been used extensively in relation to environmental concern (Castro 2006), including public understandings of biotechnology, hydrogen energy, and environmental risk (Bauer and Gaskell 2002, 2008, Castro and Gomes 2005, Kronberger and Wagner 2007, Sherry-Brennan et al. 2010, Callaghan et al. 2012).

Social representations are argued to be "a system of values, ideas and practices" (Moscovici 1973:xiii) concerted through interactions between individuals, groups, institutions, and the media. From this perspective, behavior is not causally related to beliefs (as is the case in many other psychological theories); rather, beliefs and behaviour coexist as part of the system of meaning used to understand an issue. These systems of meaning serve as tacit or implied frameworks that direct and inform verbal and nonverbal communications by defining the parameters for debate and dialog around the issue. People may be aware of how the issue is understood by other people (that is, how it is socially represented) even though they themselves do not agree with this (Moloney et al. 2005).

Central to this theoretical approach is the premise that social representations are not a vulgarization, distortion, or diffusion of scientific knowledge; rather, they are how "objects are understood in the public domain" (Bauer and Gaskell 2008:338; Callaghan et al. 2012). By this we mean that lay, or nonscientific, knowledge is not viewed as incorrect or mistaken but as a valid knowledge system in its own right. This distinction underscores how the values and beliefs of a group or community sculpt scientific knowledge to make it meaningful such that it may be qualitatively different from its scientific counterpart (Bauer and Gaskell 2008).
Scientific and nonscientific knowledge represent different modes of thinking, each of which is argued to reflect the values and beliefs central to that mode of thought. This approach does not suggest exclusivity in how an issue is understood; rather, it suggests that bi-directional transmission of knowledge occurs such that one mode of thinking is influenced by the other. Likewise, scientists are part of the community, and community members are scientists (Farr and Marková 1995). Thus, one of our interests is in the extent to which understandings of climate change are delineated by different modes of thought represented by scientific and nonscientific knowledge.

Different segments of society are likely to interact in diverse ways and at varying levels of intensity with concepts such as climate change. Arguably, individually and as communities of practice, scientists working on climate change engage with the concept more frequently than do distinct branches of government and many in the general public. Thus, we might expect different aspects of a representation, or indeed different representations, to be elicited by these different social groups (Wolf and Moser 2011).

\section{Climate change, social representations, and the media}

Abstract, complex, and often inaccessible climate science is simplified and sensationalised by the media (Höijer 2010). As a disseminated product, media communication is often perceived to be unidirectional: that is, it is often assumed that the producers of the media disseminate the news to the receivers of the media. However, mass media communications are underpinned by representational systems, and because the producers and the receivers reside within the same historicity, both the producers and receivers construct and receive media communications (Rouquette 1996, Moloney 2007). These shared representations are situated between stasis and transition; they are dynamic and malleable, making them susceptible to influence by those who have the agency and resources to proliferate one version of events over others (Jovchelovitch 1997, Wagner 1998, Moloney 2007).

Marked differences can be seen not only in the amount of coverage given by different media sources to climate change, but to the version of the climate change story told (Doulton and Brown 2009, Olausson 2009). For example, by anchoring the unknown risks of climate change to representations of familiar or known risks such as illness, death, and terror, the Swedish media has arguably emotionalized the climate change debate by presenting recognizable images of wild animals as innocent victims or icons of climate change (Höijer 2010). Conversely, the American media reporting of climate change has downplayed risks of climate change by amplifying perceptions of scientific uncertainty, providing fuel for climate scepticism and supporting dominant economic discourse (Boykoff 2007). In Australia, where our research was conducted, media reporting of climate change has emphasized policy debates that deviate significantly from climate science (McManus 2000, Gascoigne 2008), highlighting the complex interactions between science, government, and the public (Henderson-Sellers 1998). Media portrayals of scientific uncertainty have acted to segregate and distance climate scientists from the public (Zehr 2000). This segregation may have exacerbated the perception of climate scientists as out of touch with the public and unable to convey complex scientific information to the general population in a way that is engaging, understandable, or personally relevant. Thus, our aims were: (1) 
to explore Australian understandings of climate change through the framework of social representations theory, and (2) to investigate whether (and how) representations of climate change differ across community, governance, and scientific segments of society.

\section{METHODS}

\section{Data collection}

We used a word association task to explore socially constructed understandings of climate change. In this task, participants were asked to "write down the first words that come to mind when you think about climate change." This technique is said to elicit spontaneous responses that are less influenced by considerations of political correctness than those derived from more formalized means such as focus groups or Likert scales (Marková 1996).

The word association task was included in two online surveys. The first survey was administered online in July and August 2010, with respondents from across metropolitan, regional, and rural Australia $(N=5036)$. The second survey was administered on three separate occasions with different focal audiences each time. In the first application (June and July 2010), respondents were participants at a scientific conference on climate change and adaptation $(N=103)$. The second application (administered in October and November 2010) was with the Victoria State Government Department of Sustainability and Environment ( $N$ $=68$ ). The final application captured responses from members of the public living in coastal regions of the eastern and southern seaboard of Australia in April $2010(N=229)$. In the first survey, respondents were limited to three responses to the word association question. In the second survey, respondents were allowed to write as many responses as they wished. Only the first three responses made by all participants were analyzed. Both surveys collected general demographic information such as age, gender, and occupation.

\section{Data preparation}

In total, 8650 elicitations (that is, words/phrases given by respondents) were collected across all data sets. Self-identified occupation/population group was used to categorize the data. In line with the focus of the study, respondents who identified themselves as either a scientist, researcher, or academic were coded into a Scientist/Academic/Researcher group; those whose self-identification related to government were coded as Government employee, and all other respondents were coded as Community member. Hereafter, these codings are referred to as groups.

To preserve patterns of responses distinctive to each group, elicitations were homogenized within each group. That is, semantically similar words, plurals, singular, and mis-spelled words were categorized under the most frequently occurring elicitation and standardized across all groups using GTEA software (Moloney et al. 2012). The number of elicitations retained after the data were homogenized was smaller than the original number of elicitations for each group (Table 1).

\section{Data analysis}

Frequency magnitude

Frequency of elicitations for each word category were calculated and converted to frequency magnitude. Frequency magnitude is a percentage measure of the frequency count for each category relative to the magnitude of the data set within which the category occurs, where frequency magnitude $=100 /($ sum of all frequencies in data set $\times$ raw frequency of term). This allows meaningful comparisons to be made between categories across data sets (Callaghan et al. 2012).

Table 1. Number of elicitations of word categories associated with climate change for three respondent groups.

\begin{tabular}{lcccc}
\hline \hline \multirow{2}{*}{ Data set } & \multicolumn{3}{c}{ Respondent group } & \\
\cline { 2 - 4 } & $\begin{array}{c}\text { Scientists/ } \\
\text { academics/ } \\
\text { researchers }\end{array}$ & $\begin{array}{c}\text { Government } \\
\text { employees }\end{array}$ & $\begin{array}{c}\text { Community } \\
\text { members }\end{array}$ & Total \\
\hline Raw data & 458 & 554 & 7838 & 8650 \\
Cleaned & 343 & 350 & 6253 & 6946 \\
data & & & & \\
\hline
\end{tabular}

\section{Split plots}

The word category frequency magnitudes were then subjected to split plot analysis. The split plot analysis examines the stability of the pattern of word categories across the three groups. In particular, it shows the extent to which the frequency pattern for each word category reflected consensus in that each word was elicited by many participants when they thought about climate change. This is to be contrasted with a frequency pattern that shows idiosyncratic and unsustained responses that are caused by random elicitations of the word or participants repeatedly giving the same word.

A split plot was created for the first 31 most frequently occurring word categories across the sample, accounting for $46 \%$ of all words elicited. The split plot gives the frequency magnitude profile at every 100 participants. A scree-like plot of the frequency magnitude showed a concave pattern of frequency distribution to the 31 st most frequently occurring word followed by a distinct drop in the pattern of responding, indicative of consensual vs. idiosyncratic responses (see Wagner 1997, Moloney et al. 2005).

\section{RESULTS}

\section{Respondents: socio-demographic characteristics}

Respondents of the first survey comprised $51.2 \%$ females and $48.8 \%$ males. Fifty-six percent described their location as capital city, $30 \%$ as regional town, and $14 \%$ as rural area. The age profile of respondents was: $5.2 \%<24$ years old, $14 \% 25-34,16.6 \% 35-$ $44,20.7 \% 45-54,22.1 \% 55-64,17.4 \% 65-74,3.8 \% 75-84$, and $0.3 \% \geq 85$ years old. The demographic profile of respondents corresponded closely with the known population characteristics of Australians (Australian Bureau of Statistics 2010). The second survey comprised $51 \%$ females and $48 \%$ males, with the remainder of unknown gender. The age profile of respondents was: $3.1 \% \leq$ 25 years old, $22.9 \% 26-35,22.5 \% 36-45,23.1 \% 46-55,18.3 \% 56-$ $65,9.8 \% \leq 65$ years old. Data on location were not collected.

\section{Word categories associated with climate change: all groups}

We developed a split plot for the first 31 most frequently occurring word categories across all respondent groups (Fig. 1). Two crucial properties of the data can be identified using these plots. Firstly, the plots enable visualization of the noise in the data set; that is, 
Fig. 1. A split plot for the first 31 most frequently occurring word categories associated with climate change for three respondent groups: scientists/academics/researchers, government employees, and community members. Categories are ordered by frequency magnitude across all three groups.

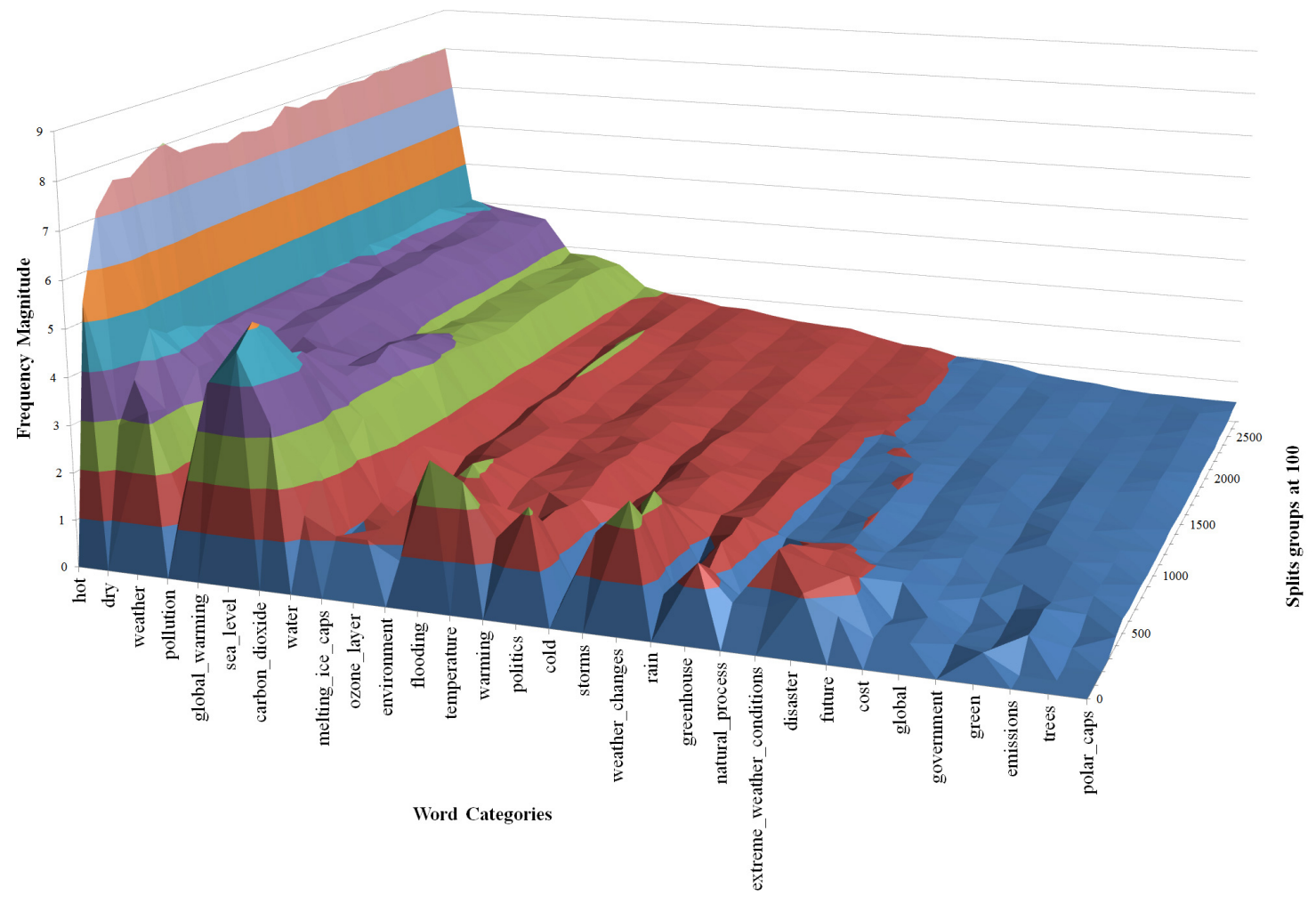

the peaks in the data profile that were caused by what are termed idiosyncratic responses such as respondents repeatedly giving the same word. This type of response, and the ensuing peak, is not indicative of a consistent pattern of responding and disappears as the number of respondents in the analysis increases. This is exemplified by the categories "flooding" and "sea-level", which have initial frequency spikes that are not maintained at the 2500 increment (Fig. 1).

Secondly, the split plot enables us to identify the relative importance of each word category to each other word category. For example, the frequency magnitude of "hot" is markedly greater than that for "emissions" (Fig. 1). Once the profile of each word category is level, it indicates that the sample is of sufficient size to overcome the influence of noise in the data set (see Callaghan et al. 2012 and Moloney et al. 2012 for further details on split plots and the use of frequency magnitude). The effect of this can be observed in virtually all 31 word categories at the 2500th increment (Fig. 1) and specifically for "hot" by the 1000th increment (Fig. 2).

The relevance of these two properties to our current data is shown, firstly, in the consistent magnitude of "hot" in comparison to all other word categories, and secondly, in the magnitude and stability of the split profile for the first nine words, i.e., "hot", "dry", "weather", "pollution", "global-warming", "sea-level", "carbon-dioxide", “water", and "melting-ice-caps", in relation to all other words. Further analyses were conducted to determine whether these findings were differentiated by respondent group.

\section{Word categories associated with climate change: by group}

To observe between-group differences, we calculated the frequency magnitude of the elicitations by each group separately. This ensured that any bias created by the different sample sizes was minimized. The top 30 terms (based on summing the frequency magnitude across all three groups) were retained for further analysis. Following Nenadic and Greenacre (2007), a correspondence analysis was performed on the frequency magnitude of the elicitations. The first two axes accounted for all of the variance in the data: 55.4 and $44.6 \%$, respectively (Fig. 3). Terms that were more likely to be used by government respondents, and which contributed strongly to the first axis, included "challenge", "disaster", "dry", "environment", "foodsecurity", "future", "sea-level", "uncertainty", and "water"(Figs. 3 and 4). Terms frequently used by the general public and by academics included "ability-to-adapt", "impact", and "inevitable". Not surprisingly, government respondents related climate change to issues and impacts they might expect to have to deal with such as "disaster", "environment", "food-security", "future", and "water".

Scientists and Community members' conceptualizations of climate change had more in common than either group had with those of Government respondents (Figs. 3 and 4). Both groups 
Fig. 2. Split profile of the 10 most frequently occurring word categories associated with climate change for three respondent groups: scientists/academics/researchers, government employees, and community members. Categories are ordered by frequency magnitude across all three groups.

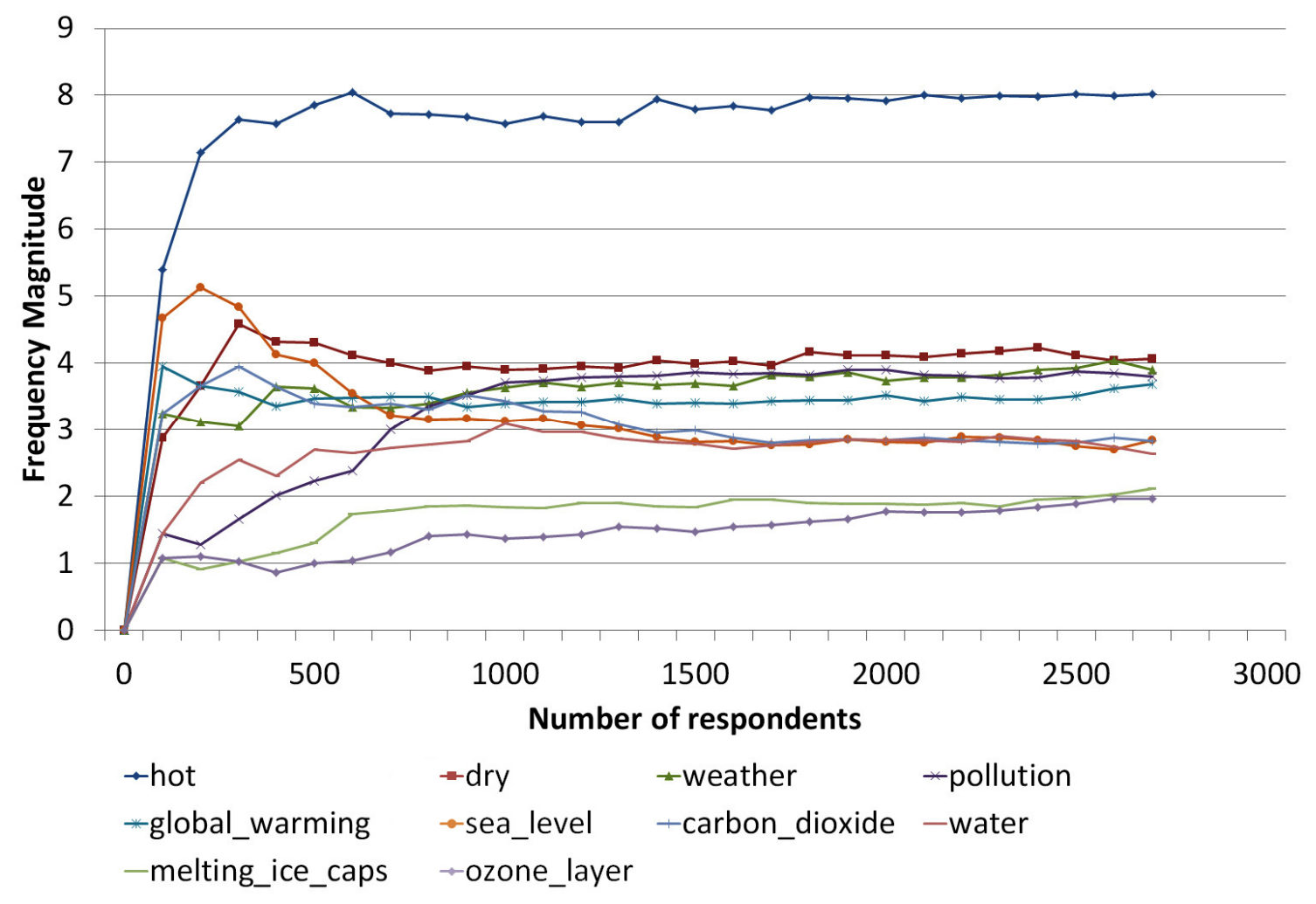

were more likely to use the following terms than were Government respondents: "flooding", "natural-process", "rain", "politics", "storms", "temperature", and "warming". Interestingly, these terms suggest causality (natural-process), effects (flooding, rain, storms, temperature), and social responses (politics).

However, there were also differences in responses between Community members and Scientists. Scientists associated climate change with attributes of weather such as "extreme-weatherconditions" and "weather-changes," and the nature of climate change in terms of "uncertainty", "inevitability", and "abilityto-adapt". In contrast, Community members associated climate change with a possible causal factor, "pollution", and with biophysical consequences, "dry", "water", and "melting-icecaps".

Aside from the 18 word categories common to all three groups, there were a number of word categories common to just two of the groups (Figs. 3 and 4). Scientists shared only one word category with Community members that was not elicited by Government employees: "warming". On the other hand, Scientists and Government employees shared four word categories, of a fairly technical nature, that were not elicited from Community members: "ability-to-adapt", "catastrophe", "foodsecurity", and "uncertainty". Government employees shared two word categories with Community that were not elicited from Scientists: "future" and "environment". The words "hot", "dry", and "global-warming" had the highest elicitations across all three groups (Figs. 1 and 2).

\section{DISCUSSION}

Our analyses of the word association responses suggest there is a common frame of reference used by all three groups in relation to climate change. Juxtaposed with this common frame of reference were responses specific to each group.

For the majority of our respondents, words describing the perceived effect of climate change on the physical environment typified their responses: "hot", "dry", "sea-levels-rising", "pollution", "weather", "water", "temperature", "storms", and "melting-ice-caps". In addition to these were responses that arguably identified less tangible impacts, albeit still physical, such as "global-warming", "carbon-dioxide", and "ozone-layer". This common frame of reference suggests that when people read, discuss, or simply think about climate change, they do so in reference to these perceived physical impacts.

Theoretically, these results suggest an emergent representational field of ideas around climate change that, in concert, allow engagement with this issue in that they provide an arena for dispute (Potter and Billig 1992). We use the word emergent because elicitations around the physical impacts of climate change were diverse and ranged in descriptive content from "hot" to "melting-ice-caps", i.e., from what is experienced to what is vicariously experienced through the media.

On the basis of these results, we argue that in Australia, climate change is now a tangible issue (see O'Neill and Hulme 2009) through this frequently occurring, consensual association with 
Fig. 3. Correspondence analysis biplot for the 30 most frequently occurring word categories associated with climate change within each of three respondent groups: scientists/academics/researchers, government employees, and community members.

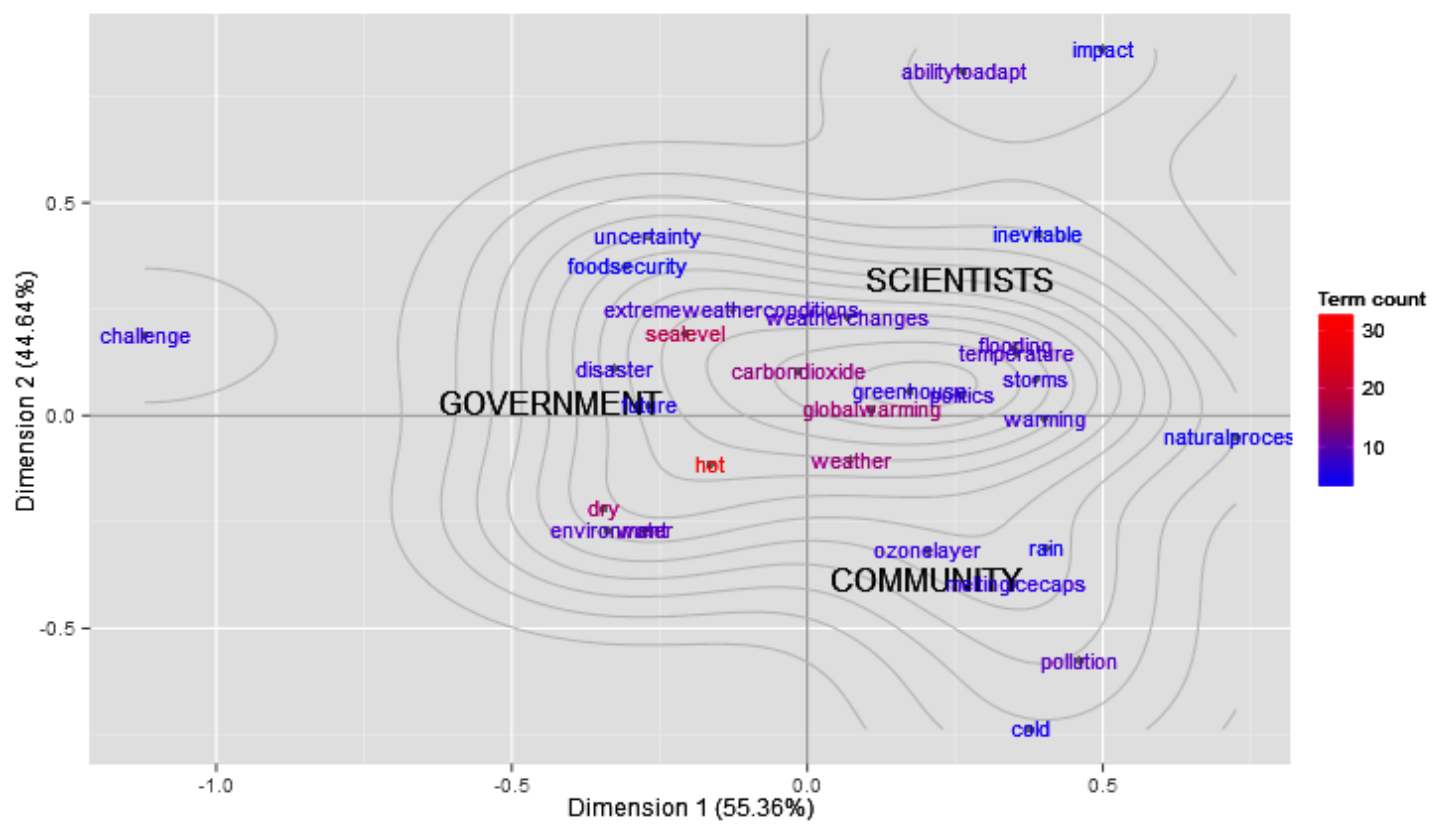

certain perceived physical impacts. By saying this, we are not implying that respondents agree that climate change causes these impacts; rather, what we are arguing is that there is consensus and that these perceived physical impacts are now defining the parameters of discussion around climate change. Respondents may not agree with these associations but nonetheless are aware that these associations exist. The prevalence of the association "ozone-layer" demonstrates this distinction nicely: whereas respondents might not agree that ozone depletion is an actual physical consequence of climate change, they are nevertheless aware of the conflation of the two issues (climate change and the ozone layer). The distinction between awareness and agreement is important because it is this consensual framework of meaning associated with climate change that allows dilemmatic thinking to occur. That is, contradictory elements within a representation can lead to issue ambivalence and shifting and inconsistent views, which characterize the constructive nature of social thought (Billig 1987, 1991).

The development of climate change as a tangible issue in Australia with an associated consensual framework of meaning is encouraging because it suggests the possibility for more structured public debate. However, the preponderance of associations with weather (rather than climate) could be some cause for concern. Scientists, Government employees, and Community members shared a number of word categories related to weather. This effect may seem fairly innocuous, but the conflation of daily weather events with climate changes across these three groups might suggest a lack of coherent understanding about climatic change. Indeed, local weather patterns have been shown to influence people's beliefs in anthropogenic climate change. Personal experience of fluctuating local weather can direct attention selectively to communications about climate change, thereby influencing individuals' judgements (Egan and Mullin 2010).

Juxtaposed with this consensual framework were responses specific to each of the three groups. Theoretically, these groupspecific responses might be interpreted as a manifestation of the consensual framework in terms of the practices, ideas, language, and behavior of each group. The reasons for the perceived physical impacts of climate change, for example, were not necessarily perceived by the Community members as anthropogenic in origin, whereas the Government employees appear to be raising concerns over financial consequences and risks posed by these physical impacts. In contrast, Scientists use words such as mitigation and carbon management, suggesting that their focus is on how these physical impacts might be mediated by interventions.

\section{The iconography of climate change}

The distinctive association of "melting-ice-caps" elicited by all groups, along with associations such as "cold" by the Community members, can be interpreted as reflecting the iconography of climate change (see Nicholson-Cole 2005, O'Neill and Hulme 2009). Doyle (2007) argues that the visual language of climate change is dominated by images of disintegrating ice-shelves, melting glaciers, and stranded polar bears, typically used to document the impacts of rising temperatures and make the phenomenon of climate change more tangible (see also Manzo 2010). Such imagery, however, does not convey the invisible nature of the risk and minimizes the presence of humans and daily experiences (Doyle 2009). Of importance is that whereas the proliferation of these types of images, typically through the 
Fig. 4. Histogram of frequency magnitude for each word category associated with climate change within each of three respondent groups: scientists/academics/researchers, government employees, and community members.

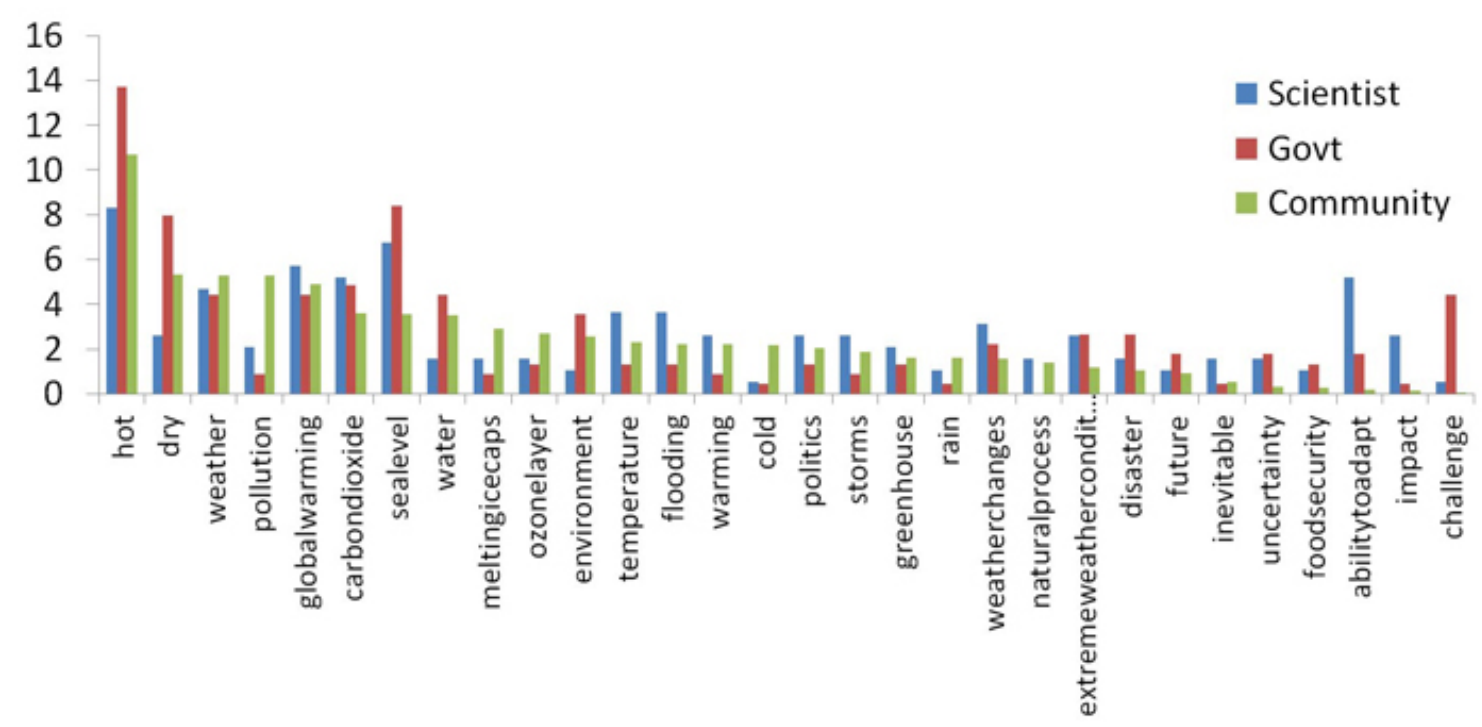

media, is intended to warn of warming temperatures, they may very well have the opposite effect if, as in Australia, they have seemingly little to do with on-the-ground impacts.

To conclude, as evidence mounts that many impacts of climate change can no longer be avoided, scientific and research institutions have shifted from an almost exclusive focus on climate change mitigation to one inclusive of adaptation (Preston and Stafford-Smith 2009): how human beings can best anticipate and respond to inevitable and predicted shifts in climatic conditions and their associated biophysical impacts. Accordingly, "adapting to climate change" is a phrase that has become increasingly used by scientists working in the climate change arena. However, do those who are not scientists working in the climate change arena really understand what adapting to climate change means? We note the absence of "adaptation" from the community word association responses, leading us to ponder whether scientific communications about responding to climate change might be missing the mark. Our data suggest that the public is now defining what the impacts of climate change might be and, as evidenced by recent research (see for example, Leiserowitz et al. 2010), are now expressing uncertainty about whether the causes of these impacts are anthropogenic in origin.

As to whether there is division between the scientific and nonscientific communities over how climate change is understood, our results suggest that climate change for most people, irrespective of the group with which they identify, is still socially defined by its physical impact. This social definition likely serves as the reference point or parameter in dialogs around this issue.

Responses to this article can be read online at: http://www.ecologyandsociety.org/issues/responses. php/6592

\section{Acknowledgments:}

The authors gratefully acknowledge the financial support of the Australian Commonwealth Scientific and Industrial Research Organisation (CSIRO) and their Climate Adaptation Flagship. We are particularly grateful to Iain Walker of CSIRO for his continued support, and we thank Aditi Mankad, John Gardner, and two anonymous reviewers for their suggestions, which helped strengthen the paper.

\section{LITERATURE CITED}

Australian Bureau of Statistics. 2010. Australian demographic statistics, Dec 2013. Catalogue Number 3101.0. Australian Bureau of Statistics, Canberra, Australia. [online] URL: http:// www.abs.gov.au/ausstats/abs@.nsf/mf/3101.0.

Australian Public Services Commission. 2007. Tackling wicked problems: a public policy perspective. Australian Government, Canberra, Australia. [online] URL: http://www.enablingchange. com.au/wickedproblems.pdf.

Baer, P., and J. S. Risbey. 2009. Uncertainty and assessment of the issues posed by urgent climate change. An editorial comment. Climatic Change 92(1-2):31-36. http://dx.doi.org/10.1007/ s10584-008-9529-3

Bardsley, D. K., and N. D. Wiseman. 2012. Climate change vulnerability and social development for remote indigenous communities of South Australia. Global Environmental Change 22(3):713-723. http://dx.doi.org/10.1016/j.gloenvcha.2012.04.003

Bauer, M. W., and G. Gaskell, editors. 2002. Biotechnology: the making of a global controversy. Cambridge University Press, Cambridge, UK.

Bauer, M. W., and G. Gaskell. 2008. Social representations theory: a progressive research programme for social psychology. Journal 
for the Theory of Social Behaviour 38(4):335-353. http://dx.doi. org/10.1111/j.1468-5914.2008.00374.X

Billig, M. 1987. Arguing and thinking: a rhetorical approach to social psychology. Cambridge University Press, Cambridge, UK.

Billig, M. 1991. Ideology and opinions: studies in rhetorical psychology. Sage, London, UK.

Boykoff, M. T. 2007. From convergence to contention: United States mass media representations of anthropogenic climate change science. Transactions of the Institute of British Geographers 32(4):477-489. http://dx.doi.org/10.1111/

j.1475-5661.2007.00270.x

Callaghan, P., G. Moloney, and D. Blair. 2012. Contagion in the representational field of water recycling: informing new environment practice through social representation theory. Journal of Community and Applied Social Psychology 22(1):20-37. http://dx.doi.org/10.1002/casp.1101

Castro, P. 2006. Applying social psychology to the study of environmental concern and environmental worldviews: contributions from the social representations approach. Journal of Community and Applied Social Psychology 16(4):247-266. http://dx.doi.org/10.1002/casp.864

Castro, P., and I. Gomes. 2005. Genetically modified organisms in the Portuguese press: thematization and anchoring. Journal for the Theory of Social Behaviour 35(1):1-17. http://dx.doi. org/10.1111/j.0021-8308.2005.00261.x

Doulton, H., and K. Brown. 2009. Ten years to prevent catastrophe? Discourses of climate change and international development in the UK press. Global Environmental Change 19 (2):191-202.

Doyle, J. 2007. Picturing the clima(c)tic: Greenpeace and the representational politics of climate change communication. Science as Culture 16(2):129-150. http://dx.doi.org/10.1080/09505430701368938

Doyle, J. 2009. Seeing the climate? The problematic status of visual evidence in climate change campaigning. Pages 279-298 in S. I. Dobrin and S. Morey, editors. Ecosee: image, rhetoric, nature. State University of New York Press, Albany, New York, USA.

Dunlap, R. E., G. H. Gallup Jr., and A. M. Gallup. 1993. Of global concern: results of the health of the planet survey. Environment: Science and Policy for Sustainable Development 35 (9):7-39. http://dx.doi.org/10.1080/00139157.1993.9929122

Egan, P. J., and M. Mullin. 2010. Turning personal experience into political attitudes: the effect of local weather on Americans' perceptions about global warming. Self-published report. [online] URL: http://government.arts.cornell.edu/assets/psac/fa10/ Egan PSAC Sep24.pdf.

Farr, R. M., and I. Marková. 1995. Professional and lay representations of health, illness and handicap: a theoretical overview. Pages 93-111 in I. Marková and R. M. Farr, editors. Representations of health, illness and handicap. Harwood Academic Publishers, Chur, Switzerland.

Gascoigne, T. 2008. Climate change: "the" issue in the Australian national election 2007? Science Communication 29(4):522-531. http://dx.doi.org/10.1177/1075547008316306
Henderson-Sellers, A. 1998. Climate whispers: media communication about climate change. Climatic Change 40 (3-4):421-456. http://dx.doi.org/10.1023/A:1005384523305

Höijer, B. 2010. Emotional anchoring and objectification in the media reporting on climate change. Public Understanding of Science 19(6):717-731. http://dx.doi.org/10.1177/0963662509348863

Jovchelovitch, S. 1997. Peripheral communities and the transformation of social representations: queries on power and recognition. Social Psychology Review 1(1):16-26.

Kronberger, N., and W. Wagner. 2007. Inviolable versus alterable identities: culture, biotechnology, and resistance. Pages 177-196 in G. Moloney and I. Walker, editors. Social representations and identity: content, process, and power. Palgrave Macmillan, New York, New York, USA.

Lazarus, R. J. 2009. Super wicked problems and climate change: restraining the present to liberate the future. Cornell Law Review 94:1153-1234. [online] URL: http://www.lawschool.cornell.edu/ research/cornell-law-review/upload/Lazarus.pdf.

Leiserowitz, A. A. 2006. Climate change risk perception and policy preferences: the role of affect, imagery, and values. Climatic Change 77(1-2):45-72. http://dx.doi.org/10.1007/s10584-006-9059-9

Leiserowitz, A., E. Maibach, and C. Roser-Renouf. 2010. Climate change in the American mind: Americans' global warming beliefs and attitudes in January 2010. Yale Project on Climate Change. Yale University and George Mason University, New Haven, Connecticut, USA. [online] URL: http://e360.yale.edu/images/ digest/AmericansGlobalWarmingBeliefs2010.pdf.

Lima, M. L., and P. Castro. 2005. Cultural theory meets the community: worldviews and local issues. Journal of Environmental Psychology 25(1):23-25. http://dx.doi.org/10.1016/j.jenvp.2004.11.004

Lorenzoni, I., A. A. Leiserowitz, and M. Doria. 2006. Crossnational comparisons of image associations with "global warming" and "climate change" among laypeople in the United States of America and Great Britain. Journal of Risk Research 9 (3):265-281. http://dx.doi.org/10.1080/13669870600613658

Lorenzoni, I., S. Nicholson-Cole, and L. Whitmarsh. 2007. Barriers perceived to engaging with climate change among the UK public and their policy implications. Global Environmental Change 17(3-4):445-459. http://dx.doi.org/10.1016/j.gloenvcha.2007.01.004

Lorenzoni, I., N. F. Pidgeon, and R. E. O'Connor. 2005. Dangerous climate change: the role for risk research. Risk Analysis 25(6):1387-1398. http://dx.doi.org/10.1111/ j.1539-6924.2005.00686.X

Manzo, K. 2010. Imaging vulnerability: the iconography of climate change. Area 42(1):96-107. http://dx.doi.org/10.1111/ j.1475-4762.2009.00887.x

Marková, I. 1996. Towards an epistemology of social representations. Journal for the Theory of Social Behaviour 26 (2):177-196. http://dx.doi.org/10.1111/j.1468-5914.1996.tb00528. $\underline{x}$

Marková, I. 2008. The epistemological significance of the theory of social representations. Journal for the Theory of Social Behaviour 38(4):461-487. http://dx.doi.org/10.1111/j.1468-5914.2008.00382. $\underline{x}$ 
McManus, P. A. 2000. Beyond Kyoto? Media representation of an environmental issue. Australian Geographical Studies 38 (3):306-319. http://dx.doi.org/10.1111/1467-8470.00118

Moloney, G. 2007. Social representations and the politically satirical cartoon: the construction and reproduction of the refugee and asylum-seeker identity. Pages 61-84 in G. Moloney and I. Walker, editors. Social representations and identity: content, process, and power. Palgrave Macmillan, New York, New York, USA.

Moloney, G., R. Hall, and I. Walker. 2005. Social representations and themata: the construction and functioning of social knowledge about donation and transplantation. British Journal of Social Psychology 44(3):415-441. http://dx.doi. org/10.1348/014466605X42246

Moloney, G., J. Williams, and D. Blair. 2012. Cognitive polyphasia, themata and blood donation: between or within representation. Papers on Social Representations 21:4.1-4.12.

Moscovici, S. 1973. Foreword. Pages ix-xiv in C. Herzlich, editor. Health and illness: a social psychological analysis. Academic Press, London, UK.

Moscovici, S. 1984. The phenomenon of social representations. Pages 3-69 in R. M. Farr and S. Moscovici, editors. Social Representations. Cambridge University Press, Cambridge, UK, and Maison des Sciences de l'Homme, Paris, France.

Nenadic, O., and M. Greenacre. 2007. Correspondence analysis in R, with two- and three-dimensional graphics: the CA package. Journal of Statistical Software 20(3):1-13.

Nicholson-Cole, S. A. 2005. Representing climate change futures: a critique on the use of images for visual communication. Computers, Environment and Urban Systems 29(3):255-273. http:// dx.doi.org/10.1016/j.compenvurbsys.2004.05.002

Noble, D., and T. Bennett. 2007. Climate change: a wicked problem (part 2). Municipal World, Nov 2007:57-59.

O’Neill, S. J., and M. Hulme. 2009. An iconic approach for representing climate change. Global Environmental Change 19 (4):402-410. http://dx.doi.org/10.1016/j.gloenvcha.2009.07.004

O’Neill, S. J., and S. Nicholson-Cole. 2009. "Fear won't do it": promoting positive engagement with climate change through visual and iconic representations. Science Communication 30 (3):355-379. http://dx.doi.org/10.1177/1075547008329201

Olausson, U. 2009. Global warming_global responsibility? Media frames of collective action and scientific certainty. Public Understanding of Science 18(4):421-436. http://dx.doi. org/10.1177/0963662507081242

Potter, J., and M. Billig. 1992. Re-representing representations discussion of Räty \& Snellman. Papers on Social Representations 1:15-20.

Preston, B., and M. Stafford-Smith. 2009. Framing vulnerability and adaptive capacity assessment: discussion paper. CSIRO Climate Adaptation Flagship Working Paper 2. CSIRO, Canberra, Australia. [online] URL: http://www.csiro.edu.au/files/ files/ppgt.pdf.
Rouquette, M.-L. 1996. Social representations and mass communication research. Journal for the Theory of Social Behaviour 26(2):221-231. http://dx.doi.org/10.1111/j.1468-5914.1996. tb00530.x

Sherry-Brennan, F., H. Devine-Wright, and P. Devine-Wright. 2010. Public understanding of hydrogen energy: a theoretical approach. Energy Policy 38(10):5311-5319.

Wagner, W. 1997. Word associations in questionnaires: a practical guide to design and analysis. Series in Social Research Methods 3. London School of Economics, London, UK.

Wagner, W. 1998. Social representations and beyond: brute facts, symbolic coping and domesticated worlds. Culture and Psychology 4(3):297-329. http://dx.doi.org/10.1177/1354067X9800400302

Weingart, P., A. Engels, and R. Pansegrau. 2000. Risks of communication: discourses on climate change in science, politics, and the mass media. Public Understanding of Science 9 (3):261-283. http://dx.doi.org/10.1088/0963-6625/9/3/304

Whitmarsh, L. 2011. Scepticism and uncertainty about climate change: dimensions, determinants and change over time. Global Environmental Change 21(2):690-700. http://dx.doi.org/10.1016/ j.gloenvcha.2011.01.016

Wolf, J., and S. C. Moser. 2011. Individual understandings, perceptions, and engagement with climate change: insights from in-depth studies across the world. WIREs Climate Change 2 (4):547-569. http://dx.doi.org/10.1002/wcc.120

Zehr, S. C. 2000. Public representations of scientific uncertainty about global climate change. Public Understanding of Science 9 (2):85-103. http://dx.doi.org/10.1088/0963-6625/9/2/301 